Paidéia, 2004, 14(29), 287-299

\title{
IMAGENS VISUAIS COMO RECURSOS PEDAGÓGICOS NA EDUCAÇÃO DE UMAADOLESCENTE SURDA: UM ESTUDO DE CASO ${ }^{1}$
}

\author{
Clarisse Alabarce Nery² \\ Cecília Guarnieri Batista \\ FCM - Universidade Estadual de Campinas
}

\begin{abstract}
Resumo: O uso de imagens visuais vem sendo ressaltado por Reily como recurso pedagógico no trabalho com crianças surdas. No presente estudo, essa proposta foi testada com uma jovem surda, visando observar possíveis contribuições do uso de imagens visuais no processo de aprendizagem dessa jovem, durante os atendimentos em pedagogia, que constituem parte das atividades de que ela participa em clínica-escola especializada. Foram realizadas três sessões pedagógicas, com utilização sistemática de representações visuais (desenho, fotos, pinturas). As sessões foram filmadas, transcritas e analisadas de modo qualitativo. Os resultados indicaram o desenvolvimento de uma prática discursiva com diálogos extensos, abordando elementos descritivos e estabelecendo relações e inferências entre os assuntos propostos. O estudo confirmou achados anteriores sobre o efeito facilitador da imagem visual na educação do surdo e trouxe a discussão sobre as dificuldades de inclusão social dos jovens surdos.
\end{abstract}

Palavras-Chave: Imagens Visuais na Educação; Educação e Surdez; Inclusão Educacional.

\section{VISUAL IMAGES AS PEDAGOGICAL RESOURCES IN THE EDUCATION OF A DEAF TEENAGER: A CASE STUDY}

\begin{abstract}
Visual images have been adopted by Reily as a pedagogical resource with deaf children. In the present study, this use was tested with a deaf teenager girl. The objective was to identify possible contributions of the use of visual images in her learning process. The study was conducted during the meetings with the pedagogue, at an institution for especial education. For the three meetings analyzed, visual images were systematically used (drawings, photos, pictures). The sessions were taped, transcribed and then analyzed. The results indicated the development of discursive practices with extended dialogues, that included descriptions, associations and inferences among the topics. The study confirmed previous data about the facilitating effect of visual images in the education of a deaf person. It brought forward the discussion about the difficulties of social inclusion of young deaf people.
\end{abstract}

Key-Words: Visual Images in Education; Education and Deafness; Educational Inclusion.

Ao falar em educação inclusiva tem-se que vislumbrar o âmbito que abrange tal proposta para uma política educacional. Este processo visa não só a integração social, mas tem uma dimensão bem maior, objetivando um movimento que transforme concepções sobre a diversidade humana e a participação das pessoas, com deficiência ou não, em uma sociedade em que todos sejam de fato cidadãos. Este processo tem dimensões políticas, sociais, educacionais, filosóficas que devem atender às diferenças de todas as pessoas. Neste sentido, o Estado tem responsabilidades de proporcionar condições, oferecendo oportunidades e meios para que a inclusão aconteça de fato.

Para Andretta (1999), educação inclusiva é um processo em que alunos com necessidades educativas especiais freqüentam redes comuns de ensino, que deverão estar preparadas para dar apoio, instrução, atender às potencialidades individuais e promover a

\footnotetext{
${ }^{1}$ Artigo recebido para publicação em 11/05/2004; aceito em 19/10/2004.

${ }^{2}$ Endereço para correspondência: Clarisse Alabarce Nery, Rua Macedo Soares, 807, Cidade Universitária, Campinas, SP, 13083-130, E-mail: clarisse_nery@terra.com.br
} 


\section{Clarisse Alabarce Nery}

integração com a comunidade.

Pensando e acreditando nesta concepção de educação, a política de educação inclusiva tem tomado alguns rumos em busca de soluções. No Brasil, desde a Lei de Diretrizes e Bases de 1996, há procura por uma educação inclusiva dos alunos com necessidades educativas especiais, nas classes comuns da rede regular de ensino. De acordo com Boneti (2000), numa educação inclusiva existe um espaço de diversidade e a aprendizagem acontece para cada um, conforme suas possibilidades.

A pedagogia da inclusão propõe um processo de aprendizagem cooperativo, que respeita os diferentes estilos de aprender e a singularidade dos aprendizes, reconhece os diferentes ritmos, interesses, desejos e concepções de mundo. Portanto, a pedagogia inclusiva não pretende a correção do sujeito, mas a manifestação do seu potencial, contemplando as necessidades de todos os alunos.

\section{Educação Inclusiva e Desenvolvimento da pes- soa com Deficiência}

Quando se fala em inclusão, é interessante lembrar, como diz Kassar (1999), que "é sempre em um determinado ‘mundo' (no contato com o outro) que o sujeito nasce, cresce, se desenvolve, se constitui. É este mundo (de incontáveis e encantáveis outros) que será, por ele, internalizado, no processo de sua constituição social.”(p.69). E a escola pode ser um desses mundos.

Além do conhecimento formal, a inclusão possibilita o desenvolvimento do potencial humano; nas interações sociais com os adultos pode ocorrer o aprendizado de regras, normas, valores que proporcionam experiências que serão transpostas para a vida cotidiana. Nesta relação, pode-se criar também o espaço da interlocução, da enunciação e do diálogo que favorecerá a significação do sujeito, levando o aluno a construir relações com seus parceiros por meio de brincadeiras e múltiplas atividades cooperativas e competitivas, podendo conquistar amigos, desenvolver habilidades sociais, aumentar a capacidade de controle pessoal, gerar condições para que o sujeito se signifique como autor e ator de sua história.

\footnotetext{
${ }^{3}$ Nome fictício.

${ }^{4}$ Também esta professora tem pouco domínio da língua de sinais.
}

Participando de um ambiente escolar, na interação com o outro, a criança ou o adolescente tem a oportunidade de se desenvolver como ser cultural, socializar-se, adquirir competências sociais, controle dos impulsos agressivos, a relativização dos pontos de vista. Assim, por meio das trocas com os pares e nas atividades formais e informais, é dada à pessoa com deficiência a possibilidade de construir o conhecimento, constituindo-se enquanto sujeito, sendo seu aprendizado e desenvolvimento favorecidos neste contexto de relações sociais.

Padilha (2001) considera que a pessoa com deficiência deve ser pensada em sua integridade, que ela não é a "deficiência” o tempo todo; ele afirma que ela precisa vivenciar situações significativas, expandir possibilidades e diminuir suas limitações, constituir-se como sujeito simbólico, ou seja “[...] sujeito de práticas discursivas criando e interpretando signos, dando-se a perceber e a conhecer não mais pelas incapacidades, mas pelas suas condições de funcionamento cognitivo, na e pela linguagem, com o outro, no processo dialógico [...]” (p. 135).

Especificando o tipo de aprendizado que a criança com deficiência necessita, Kassar (1999) diz: "O aprendizado escolar (praticamente silenciado pela nossa legislação educacional para pessoas que freqüentam instituições especializadas do país) pode ser um tipo de aprendizado novo na vida do sujeito, por ser acompanhado e sistematizado. Quando bem planejado, propicia seu desenvolvimento, possibilitando acesso sistematizado à cultura produzida historicamente.” ( p.86)

As perguntas que surgem, são: Como se significar como pessoa, num mundo sócio-histórico-cultural, sem que as "faltas" sejam as principais evidências? Como se tornar sujeito de sua própria história e aprendizagem, tendo limitações biológicas que trazem especificidades na participação no processo educacional?

Partindo da concepção acima para a elaboração de uma proposta pedagógica, a intervenção deve potencializar as capacidades da pessoa com deficiência, a partir do conhecimento de suas limitações biológicas, sua história de vida, seu ritmo, seu modo de aprender, seus desejos e emoções. 


\section{Crianças surdas - Propostas educacionais re- centes}

Considerando que as interações com o outro e as mediações entre os sujeitos e os signos possibilitam o aprendizado, a socialização e a significação, pode-se dizer que uma proposta pedagógica que utilize como recursos os instrumentos semióticos disponíveis na cultura estará favorecendo o aprendizado das pessoas com deficiência, fazendo com que o conhecimento e a significação do mundo aconteçam de maneira construtiva e com sentido. O desafio é, pois, torná-los acessíveis e disponíveis para os alunos com necessidades educativas especiais.

No que se refere à surdez, as propostas recentes reconhecem a Língua de Sinais como a língua do surdo, a ser adotada preferencialmente desde o berço. Essa concepção contrapõe-se à ênfase anterior no treino de fala e leitura labial, que passa a ser vista como recurso comunicativo adicional, considerandose que a aquisição da Língua de Sinais permite o uso da linguagem com todas as funções e possibilita a constituição do surdo enquanto sujeito que pensa, sente, se expressa.

De acordo com Sacks (1998), a linguagem nos possibilita o ingresso pleno no estado e cultura humanos. Por meio da língua, comunicamo-nos livremente, adquirimos e compartilhamos informações. Caso não possamos desenvolver este processo lingüístico, ficaremos incapacitados e isolados, sejam quais forem nossos desejos, esforços e capacidades inatas. Para o autor, uma das formas para o surdo ter esta aquisição é a aprendizagem da Língua de Sinais e que quanto mais cedo a criança for colocada em contato com ela, mais fluência ela terá na comunicação. $\mathrm{O}$ autor diz que "as pessoas profundamente surdas não mostram em absoluto nenhuma inclinação nata para falar. Falar é uma habilidade que tem de ser ensinada a elas, e constitui um trabalho de anos. Por outro lado, elas demonstram uma inclinação imediata e acentuada para a Língua de Sinais que, sendo uma língua visual, é para essas pessoas totalmente acessível” (p. 43). Ele afirma que na medida em que a criança faz a aquisição da Língua de Sinais, ela vai desenvolvendo o livre intercurso de pensamento, o fluxo de informação, o aprendizado da leitura e escrita e, talvez a fala.
Para Goes (2000), a linguagem é uma força de reprodução e transformação criativa, uma atividade que constitui os processos humanos, sem a qual não há encontros entre os sujeitos e formação da subjetividade. Assim, com a Língua de Sinais, o surdo constitui-se enquanto sujeito, ao desenvolver a linguagem e o pensamento, interagindo e identificando-se como ser social e histórico, apresentando condições de aprender, construir e reconstruir o conhecimento na interação com o objeto a ser conhecido; além disso, ela é "adquirida pelos surdos com naturalidade e rapidez, possibilitando o acesso a uma linguagem que permite uma comunicação eficiente e completa como aquela desenvolvida pelos sujeitos ouvintes, permitindo ao surdo um desenvolvimento cognitivo e social muito mais adequado e compatível com sua idade.” (Lacerda, 2000, p.53)

Assim, o surdo pode significar o mundo por processos semelhantes aos dos ouvintes, através de uma estrutura lingüística que permite compreender, dar sentido a fatos, objetos, sentimentos e emoções, pois a língua é o requisito básico para as ações educacionais, possibilitando a comunicação, o pensamento generalizante (Vygotsky, 1989), a inserção social e cultural.

No que se refere ao processo educacional, é importante discutir propostas que garantam o acesso à Língua de Sinais. Um dos recursos propostos envolve a adoção do intérprete na sala de aula, de tal modo que o aluno surdo recebe a informação escolar em Língua de Sinais, por meio de uma pessoa com competência nesta língua e que dá apoio ao professor. Contudo, Lacerda (2000), que vem estudando essa questão com alunos das primeiras séries escolares, considera que a presença do intérprete na sala de aula não tem garantido a aprendizagem para o aluno surdo, observando que há situações em que sua interação com o professor é reduzida, e em que a mediação pelo intérprete não a faz comparável à observada com os demais alunos. Segundo a autora, "É fundamental que a condição lingüística do sujeito surdo seja contemplada, se se pretende que ele apreenda conteúdos e desenvolva conhecimentos. Todavia, se a escola não faz concessões metodológicas e curriculares"... às suas necessidades .... "sua escolaridade deixa a desejar.” (p.81)

Assim, a questão da introdução da Língua de 


\section{Clarisse Alabarce Nery}

Sinais em contextos educacionais inclusivos continua a sugerir estudos e estratégias para sua implementação, e várias têm sido propostas para o trabalho educacional com surdos, entre elas, a utilização de imagens visuais.

O uso de material predominantemente visual na educação de crianças surdas é discutido por Reily (2003), a partir de sua experiência de ensino e pesquisa em arte-educação. A autora afirma que "crianças surdas em contato inicial com a Língua de Sinais necessitam de referências da linguagem visual com as quais tenham possibilidade de interagir, para construir significado" (p.16); ela adota uma abordagem sociocultural, que coloca o homem como um ser social, cujas relações com o mundo, com o outro e consigo mesmo são mediadas por sistemas sígnicos; nesse sentido, é importante o uso de representações visuais como estratégia de ensino numa proposta pedagógica inclusiva, pois ela favorecerá a apropriação de significados pela criança, bem como possibilita a representação mental de experiências. Ele relata um trabalho de arte-educação realizado com grupos de crianças surdas pré-escolares, de três a seis anos, no Cepre-FCM-Unicamp, em que integra uma proposta educacional que visa propiciar às crianças surdas a possibilidade de inserção em comunidade lingüística que utiliza a Língua de Sinais como principal forma de comunicação, utilizando imagens visuais (incluindo livros, fotografias, figuras de calendários, reproduções de quadros), objetivando a apropriação de sistemas de representação de natureza não verbal e a constituição da linguagem, possibilitando que possam se comunicar.

Entre os exemplos, inclui-se a atividade realizada com os livros de imagens de Eva Funari. Em uma delas, a autora/ilustradora criou situações engraçadas para um bicho: em cada página, o rabo aparece de forma inusitada, e a expressão do bicho muda de acordo com a situação criada. As crianças, estimuladas por esse livro, imitaram as caras e sinalizaram as situações denotadas pelo desenho do rabo. Em seguida, elas criaram as suas próprias possibilidades com rabos de barbantes de todos os tamanhos, sem uma única solução, e sim quantas a imaginação permitisse criar.

Reily (2003) afirma que o processo de ensino do aluno surdo se beneficia do uso das imagens visu- ais e que os educadores devem compreender mais sobre seu poder construtivo para utilizá-las adequadamente; a formação de conceitos seria facilitada utilizando representações visuais, e a sua adoção, nas atividades educacionais, auxiliaria no processo de desenvolvimento do pensamento conceitual, porque a imagem permeia os campos do saber, traz uma estrutura e potencial que podem ser aproveitados para transmitir conhecimento e desenvolver o raciocínio. A imagem exerceria as funções de descrição e de léxico, permitindo identificar a figura e até nomeá-la. Com isto, aparece a idéia subjacente do genérico versus o específico. Na linguagem verbal, a palavra possibilita a generalização e o raciocínio classificatório, e, no caso dos surdos, a representação visual poderá auxiliar nesses processos de pensamento. Além destas funções, a imagem favorece um pensamento relacional, utilizando os elementos visuais para estabelecer relações e comparações. São citados como exemplo as seqüências temporais e espaciais e as relações de causa e efeito.

Reily acrescenta, ainda, uma outra função para a imagem, lembrando que existe um aspecto lúdico na mesma. Por sua natureza polissêmica, significados diversos e às vezes incongruentes, presentes literalmente ou em sentido figurado numa cena visual, possibilitam ao surdo perceber as interfaces dos signos, compreender o humor e o absurdo da imagem. Essa compreensão poderá servir de ponte para que ele faça o mesmo na segunda língua que aprenderá na escola.

O trabalho descrito acima demonstra que as crianças surdas podem ser favorecidas em sua aprendizagem pelo uso de imagens visuais como estratégia de ensino, e sugere a pergunta sobre a possibilidade de utilização desses recursos para alunos surdos mais velhos, especialmente os que apresentem outros problemas de aprendizagem e/ou de relacionamento social. Em nosso país, os estudos sobre educação de surdos estão centrados nos alunos que estão nas primeiras séries do Ensino Fundamental, ou nos pré-escolares. Há poucos trabalhos sobre adolescentes, e sabe-se que a maioria deles apresenta defasagem na escolaridade, quando não o abandono do ensino regular. Tendo em vista que as propostas de adoção de Língua de Sinais são recentes, e estão em implantação, muitos tiveram uma história bastante truncada 
em termos educacionais. A maioria recebeu algum treinamento de fala e leitura labial; e a exposição à Língua de Sinais, em geral, não ocorreu de modo sistemático, e, portanto, sem resultados consistentes em seu desenvolvimento cognitivo e global.

Neste relato, apresenta-se um estudo de caso realizado com uma jovem surda, de 19 anos, que tinha, desde pequena, alguns comportamentos que dificultavam sua inserção escolar. O objetivo foi observar possíveis contribuições do uso de imagens visuais no processo de aprendizagem dessa jovem, durante os atendimentos em pedagogia, que constituem parte das atividades de que ela participa em clínica especializada.

\section{Método}

\section{Caracterização do sujeito}

O estudo foi realizado com Janete ${ }^{3}$, uma jovem de dezenove anos, com um quadro de surdez profunda bilateral desde bebê. Filha adotiva de mãe profissional da área da saúde, sem informações sobre o seu histórico pré-natal, a causa da surdez ou outras características da família biológica; pais adotivos com nível de escolaridade superior, padrão sócioeconômico de classe média.

Quando criança, os relatórios médicos indicavam um atraso no desenvolvimento neuropsicomotor, sem diagnóstico de patologia determinada, além da surdez. Os sintomas foram observados desde a época da adoção, com um ano e cinco meses, sendo que a criança se achava internada no hospital há meses, tratando de vários problemas de saúde, apresentando alta imunidade a todas as doenças (o que é atípico), e sem histórico que justificasse o quadro.

Segundo informações da mãe, desde pequena Janete tinha comportamentos como falta de atenção e de concentração, auto-estimulação através de movimentos repetidos (ex: balançar), e atitudes exacerbadas quando colocada em situação adversa, e sempre apresentou dificuldades de socialização. Em termos de comunicação, ela não fala, faz um pouco de leitura labial e utiliza a Língua de Sinais com pessoas da família, com a educadora e colegas.

De acordo com seu Histórico ela freqüentou berçários e escolas infantis a partir de dois anos de idade. Aos sete anos foi matriculada na escola especial para surdos, e cursou até a $4^{a}$ série do Ensino Fundamental, tendo, nesse momento, quatorze anos; houve dificuldades desde o início; com freqüência ela se recusava a fazer as tarefas e, às vezes, gritava na sala de aula; foi reprovada na 4 a série e, daí em diante freqüentou escolas especiais e particulares, por mais três anos. Depois, foi para uma clínica-escola privada.

Durante todo o período escolar teve acompanhamento nas áreas de pedagogia, fonoaudiologia, terapia ocupacional e psicologia, em clínicas particulares; a mãe disse que após muitos anos obrigando Janete a freqüentar escolas, ela desenvolveu algumas técnicas de adaptação como bom comportamento e copiar tudo o que era colocado na lousa, embora com dificuldade de compreensão. Ao mesmo tempo, começou a mostrar sintomas de prováveis doenças psicossomáticas (vômitos e dores abdominais), que cessaram quando foi para a clínica-escola e informaram-lhe que não iria retornar à escola. Durante esses anos Janete adquiriu leitura e escrita em nível elementar e algumas noções de matemática.

No presente, ela freqüenta a clínica-escola, onde participa do Grupo de Oficinas Terapêuticas (tecelagem, bordado, pintura e marcenaria) três vezes por semana, por meio período. Nesse grupo das oficinas, somente Janete é surda, e os demais participantes têm outras deficiências. Dos profissionais que atuam com ela, poucos usam a Língua de Sinais; ela participa ainda de aula individual de pintura duas vezes por semana ${ }^{4}$. Janete apresenta algumas dificuldades motoras, principalmente para execução do movimento de pinça, tem pouca força nas mãos e nos dedos, o que dificulta a escrita manual com clareza, embora não atrapalhe o manuseio de pincéis. É considerada afetiva com os colegas e profissionais que trabalham com ela, não participa de grupos de jovens, ou de outras atividades fora da clínica; tem dificuldade para criar diálogos, manter uma conversa e explorar com profundidade o assunto que está sendo discutido: seus diálogos tendem a ser curtos, sem elaboração ou transposições para novas situações.

$\mathrm{O}$ atendimento pedagógico individual, parte das atividades na clínica-escola, ocorre uma vez por semana, com duração de duas horas. Envolve a realização de atividades de leitura, escrita e raciocínio lógico, numa proposta contextualizada em relação aos 
interesses e preferências de Janete. Os diálogos são na Língua de Sinais, e ela tem certo domínio da leitura labial.

Além dessas atividades, Janete e a mãe recebem aulas particulares de Língua de Sinais Brasileira (LIBRAS) uma vez por semana, em sua casa.

\section{Procedimento de coleta de dados}

No contexto dos atendimentos, três sessões consecutivas foram selecionadas, para o presente trabalho, em que o uso de imagens visuais foi intensivo. Cada sessão teve a duração de duas horas, com programação descrita no Quadro I. As atividades foram filmadas, gravadas e transcritas.

Quadro 1: Atividades pedagógicas

\begin{tabular}{|c|c|c|}
\hline Resumo da atividade & $\begin{array}{c}\text { Duração de } \\
\text { cada atividade }\end{array}$ & $\begin{array}{c}\text { Quantidade de } \\
\text { imagens visuais } \\
\text { Apresentadas }\end{array}$ \\
\hline \multicolumn{3}{|l|}{ SESSÃO 1} \\
\hline 1- Observação de gravuras. & $35 \mathrm{~min}$ & 4 \\
\hline 2- Desenho de animais. & $10 \mathrm{~min}$ & 4 \\
\hline 3- Associação de metáforas. & $15 \mathrm{~min}$ & 17 \\
\hline 4- Produção de textos. & $1 \mathrm{~h}$ & 1 \\
\hline \multicolumn{3}{|l|}{ SESSÃO 2} \\
\hline 1- Ver imagens das fotos do livro: "Um dia daqueles". & $1 \mathrm{~h} 30 \mathrm{~min}$ & 92 \\
\hline 2- Leitura e identificação de semelhanças e diferenças de animais. & $30 \mathrm{~min}$ & 5 \\
\hline \multicolumn{3}{|l|}{ SESSÃO 3 } \\
\hline 1- Observação das fotos selecionadas do livro "Um dia daqueles". & $1 \mathrm{~h} 10 \mathrm{~min}$ & 6 \\
\hline 2- Pintura de animais, objetos ou pessoas. & $35 \mathrm{~min}$ & 4 \\
\hline 3- Produção de texto. & $15 \mathrm{~min}$ & 2 \\
\hline
\end{tabular}

\section{Análise de dados}

A interação foi centrada em aspectos observados durante a realização do trabalho e utilizados como categorias de análise.

a) Identificação e reconhecimento de atributos das figuras. Exemplo: Pintura de uma almofada Identificou que é de tecido, e que é uma pintura.

b) Reconhecimento de aspectos imediatos que a representação visual oferece. Exemplo: Pintura de cobra - Reconheceu que é uma cobra pintada, cores laranja, amarelo e preto.

c) Relações entre significado e situações do cotidiano. Exemplo: Desenho do peixe - A partir do desenho do peixe, estabeleceu-se um diálogo sobre os peixes da casa da educadora e da aluna.

d) Transposição de situações, da representação visual para a realidade. Exemplo: Foto de um leão, deitado em cima de um tronco - Relação consigo mesma, comentando que o leão está cansado, assim como ela também está.

e) Relações de significado metafórico com fatos do diaa-dia. Exemplo: Figura de um homem com a língua para fora - Relação com uma pessoa cansada.

f) Mediação da educadora com o apoio da representação visual, com perguntas e explicações e as interações da participante. Exemplo: Figura da bailarina - Comentários a respeito do seu interesse e experiências com balé e produção de texto.

Com base nas categorias destacadas, as transcrições foram examinadas e feitos comentários em relação aos diferentes episódios e fatos relevantes durante a realização das atividades. A análise teve seu foco no processo do trabalho, nas aquisições parciais observadas ao longo dos diálogos.

Com este enfoque, observou-se com quais elementos Janete trabalhou, como vivenciou as situações oferecidas e mediadas pela educadora, que tipo de contato e exploração fez do material apresentado, as relações estabelecidas com a representação visual utilizada e os seus significados.

\section{Resultados}

Resumos das atividades e trechos representativos do desempenho de Janete nas três sessões. 
As situações foram escolhidas segundo as diferentes atividades em que Janete demonstrou envolvimento, participação, diálogos mais longos e formas diversas de compreensão. É importante destacar que, em todos os diálogos, Janete usou a Língua de Sinais para se comunicar, enquanto a educadora usou Língua de Sinais e falou ao mesmo tempo. Convencionou-se, que as transcrições trazem a "fala" de ambas, embora Janete tenha se comunicado na Língua de Sinais, aqui traduzidos.

\section{SITUAÇÃO 1 - Sessão 1, atividade 1: Observar Gravuras}

Na primeira atividade proposta, Janete tinha que observar figuras de objetos e relacionar as funções dos mesmos com o que eles representavam e o material de que eram feitos. Foram utilizadas as figuras: esculturas de um galo, de um cavalo de metal, uma almofada de tecido com desenho de tartaruga, quadro com a pintura de cobra. Relato:

Figura de almofada com pintura da tartaruga -

Janete olha a figura. A educadora dirige o diálogo para o aspecto: material de que é feito. Observando a gravura (tartaruga / almofada), chamo a atenção de Janete, perguntando:

Educadora - Qual é o gesto de tecido? É roupa? Isto aqui? (apontando para a figura da almofada)

J - É tecido. (Janete mostra a blusa, várias vezes, gesto de pergunta e confirmação. É tecido)

Educadora - escreve a palavra macio e mole. (Janete mostra com sinais, que a roupa era mole e macia).

J - Janete olha para a almofada e diz: - Serve para dormir. Qual é o nome disso? Escreve o nome aqui. (aponta para o papel)

Educadora - O nome disto aqui é almofada. (escreve a palavra) - Janete, você coloca no seu sofá?

J - Sim.

Educadora - Tem almofada na sua casa, para dormir no sofá?

J - Não. (Janete olha para a palavra escrita e para a educadora, várias vezes e responde.)

$\mathbf{J}$-Você tem almofadas em sua casa?

Educadora - Na minha casa tem almofadas.

J - Quais cores?

Educadora - Na minha casa tem almofadas brancas, vermelhas e laranja. Na sua casa, Janete, tem almofadas?

$\mathbf{J}$ - Você tem almofadas iguais à da figura?

Educadora - Não, eu não tenho almofadas igual a esta, são diferentes.

$\mathbf{J}$ - (Escreve a palavra rosa, para perguntar se educadora tem almofada rosa.)

Educadora - Rosa? Não, eu não tenho! Ah! tenho rosa. No domingo eu fiz almofadas rosa na minha casa. Fiz três almofadas rosas. E na sua casa, tem almofada rosa?

J -As almofadas são velhas, precisa comprar novas.

Educadora - Jóia. Vamos lá. O nome disso aqui é almofada.

J - ( Janete escreve o nome "almofada”.) Você fez igual à outra gravura, recortou da revista. É igual às outras gravuras. Você pegou na revista? (Janete fez sinais e datilologia).

Educadora - Sim.

Iniciando com uma investigação sobre o material de que é feita (tecido), Janete fala de uma função da almofada (serve para dormir), pergunta o nome do objeto e segue-se um diálogo sobre usos e características de almofadas de sua casa e da casa da educadora.

Nesta situação, observa-se que o uso da imagem visual favorece o início de um diálogo. Janete faz relações com o seu cotidiano, a partir de um reconhecimento do objeto, estabelece significados além dos explicitados na gravura. A imagem apresentada traz a possibilidade de várias conversações, e com o apoio da mediação através de perguntas, explicações e exposição da imagem, ela toma contato com um pensar não tão literal, num movimento para criar novos conceitos e entender os diferentes sentidos das representações, elaborando relações entre elas.

SITUAÇÃO 2 - Sessão 1 - Atividade 2: Desenhar Animais

Na atividade seguinte, foi proposto que Janete 


\section{Clarisse Alabarce Nery}

desenhasse os animais solicitados - passarinho, peixe, gato e cachorro e determinasse outra função para os mesmos. Os nomes dos animais estavam escritos na mesma folha.

Janete desenha um peixe de forma bastante esquemática, apresentando difícil identificação do animal por outra pessoa. A educadora, conhecendo seu interesse por peixes, introduz uma conversa perguntando se ela tinha quadros com pintura de peixes.

Educadora - Agora, com o peixe.

J - (Janete desenha um peixe)

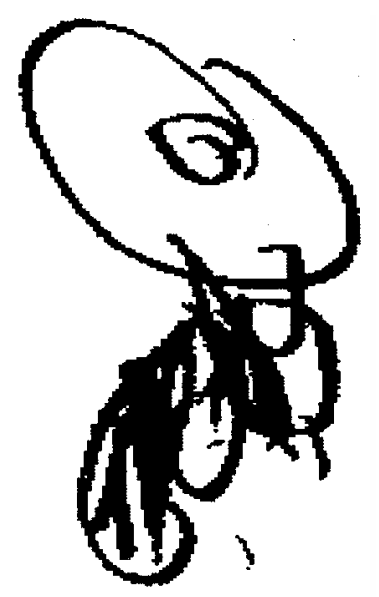

Figura 1: Desenho do Peixe

Educadora (Lendo a palavra peixe, pergunta a Janete:) - O que posso fazer com o peixe? Ele não é de verdade. Existe quadro pintado com peixes? Tem?.

J - Sim.

Educadora -Na sua casa tem quadros pintados com peixes? Pintura? Tem ou não?

(Janete olha para a educadora e presta atenção nos sinais que ela faz, sem responder às perguntas.) - Na sua casa tem peixe de verdade?

J -Tem.

Educadora - Janete, você tem peixe de verdade? Tem?

J - Sim.

Educadora - Janete, você tem aquário em casa? (Escreve a palavra aquário.)

J - Sim.

Educadora - Eu, na minha casa, tenho um aquário grande, tem muitos peixes diferentes.
J - Os peixes são grandes ou pequenos?

Educadora - Tem um pequeno, tem maiores um bem grande, tem um todo pintado de amarelo. Ele é preto pintado com amarelo, deste tamanho (mostra com sinal). E o seu aquário, tem peixes pequenos?

(Janete presta atenção à educadora falando e fazendo os sinais)

J - Sim.

Educadora - Qual a cor do peixe?

J - É laranja.

Educadora - Janete, quantos peixes tem?

J - Tem um monte!

Educadora - Um monte? Janete, você dá comida para eles?

J - Todos os dias.

A atividade foi realizada de modo completo, tendo Janete feito os desenhos dos quatro animais propostos. A partir do desenho, é mantida uma conversa sobre os aquários da educadora e de Janete, com riqueza de detalhes. Exploram as características dos peixes e seus hábitos.

Nesta atividade, Janete estabelece um diálogo que vai além das características físicas do objeto. Com a educadora realizando perguntas, ela começa a explorar outro campo conceitual, relaciona com suas vivências, seu dia-a-dia, consegue manter um diálogo com maior extensão e organização das idéias. A partir da utilização da imagem criada (desenho do peixe), a educadora estimula sua participação e ela consegue uma relação dinâmica entre conceitos e vivências.

SITUAÇÃO 3 - Sessão 1 - Atividade 3: Associação de Metáforas

A proposta desta atividade era que Janete associasse as cartas (tipo baralho) com desenhos que representavam determinadas situações (ex: pessoa parecendo cansada) com a frase que indicava o significado correspondente aos desenhos (ex: "Ficar de língua de fora”). Do conjunto de 17 cartas apresentadas, Janete fez a correspondência correta em três casos, aproximou-se do significado em cinco e não acertou nove. Educadora - (Pega a carta em que estava escrito: "Ficar de língua de fora." e lê a frase junto com Janete. Pede para Janete procurar a carta 
com o desenho correspondente.) $\mathbf{J}$ - (Janete mostra sinais de ansiedade, pega a carta correspondente e diz:) - O homem está cansado.

Janete ao observar o desenho apresentado, olha de perto e lê a frase com a educadora (sinais). Pega a carta com a figura representativa da frase e expressa sua compreensão, relacionando figura e fato a que a metáfora se refere (“O homem está cansado").

Janete consegue identificar em todas as figuras o que está desenhado em cada uma. Por exemplo, no desenho de uma orelha com uma pulga, Janete diz que a pulga está na orelha (descrição literal) e não que a pessoa está desconfiada de alguma coisa ou de alguém (captação do significado). Ela mostra interesse e, quando tem dúvida, pergunta para a educadora o significado da frase ou da palavra, fica atenta às explicações, e, com o apoio das mesmas, parece estabelecer relações, aumentando a compreensão do significado das frases.

Trabalhar com frases metafóricas é uma atividade com um nível de complexidade maior que as habitualmente apresentadas, pois exige atividade mental diversa; tendo em vista que esta foi a primeira vez que fez isto, ela parece ter obtido ganhos, escutando as explicações da educadora, fazendo perguntas e estabelecendo relações.

\section{SITUAÇÃO 4 - Sessão 1-Atividade 4: Produção} de Texto

Nesta atividade, foi proposto a Janete que observasse a gravura de uma bailarina e produzisse um texto. O trabalho iniciou com a apresentação da gravura de uma menina vestida de bailarina, com um casaco jeans curto sobreposto e usando tênis, estando escrito junto um verso de Cecília Meireles: "Esta menina tão pequenina quer ser bailarina”

Janete demonstrou grande interesse pela gravura, pois gostava de dançar. O diálogo foi direcionado para as características físicas da bailarina (roupa, sapatos) Janete questionou a adequação do tipo de roupa usada pela menina, perguntando como poderia dançar vestida daquele jeito.

J - (Janete olha a figura e aponta para o casaco, uma jaqueta de jeans). Olha os pés e aponta o tênis.

$\mathbf{J}$ - Como pode?

Ela fala sobre sua infância, dizendo que dançava balé e que ainda guarda sua roupa em casa. Diz que gosta de dançar, que assistiu a alguns espetáculos de dança.

Após esta primeira exploração da figura, a educadora fez perguntas que favorecessem a elaboração de um pequeno texto. Perguntou qual seria o nome da menina, sua idade, o que fazia... Janete disse que também gostaria de dançar. A educadora perguntou onde ela gostaria de dançar, se sozinha ou com outras pessoas, quem ela queria que fosse assistir sua dança. Janete respondeu às perguntas da educadora e, com o apoio da imagem, iniciou uma pequena construção de texto.

1- Letra de Janete

$$
\begin{aligned}
\text { PRODUGÁO TEXTUAL } \\
\text { (ESCRITA) }
\end{aligned}
$$

\section{GLGD 14 ANOS}

BaIlaRino

DANGA - JANETE QUER DANGAR

ONER: COMPINAS 
2- Letra da educadora

JANETE QUER DANCAR EM SÃO PAULO
COM OUTRAS PESSOAS.
JANETE QUER QUE SUA MÃE, SEU
PAI, A TUTI E SUAS AMIGAS CRISTINA,
SILVIA E CLARISSE VAOO VER DANCAR.

Figura 2: Produção de Texto - Menina Bailarina

A partir da gravura da bailarina, Janete consegue apontar características da menina, seu nome e idade, o que gosta de fazer. Ao observar a gravura, direciona uma conversa a seu respeito, falando de sua infância e desejos futuros em relação à dança. Com a mediação da gravura e das perguntas, inicia uma pequena produção de texto e após algumas palavras pede para a educadora escrever o restante. Ela fala (em sinais) e a educadora escreve. Ao trabalhar com a imagem da bailarina, ela faz relações de vários tipos (de significado), demonstra capacidade de perceber detalhes da roupa, de criticar a incongruência da vestimenta (jaqueta jeans e tênis), para além da observação direta, e considera que mesmo vestida de forma diferente, a menina continua sendo bailarina; depois relaciona atributos da imagem com sua vida pessoal. Aproveita a imagem e os elementos que ela traz e transpõe os mesmos para uma situação da sua vida, que aconteceu no passado. Com o apoio da imagem, no diálogo com a educadora, ela enriquece seu vocabulário e cria uma relação com a realidade, mantendo uma conversa dentro de um contexto mais amplo.

É provável que se as imagens oferecidas fossem menos relacionadas a seus interesses e vivências ela não a teria explorado tanto e estabelecido relações em outro nível.

SITUAÇÃO 5 -Sessão 2. Atividade 2: Ler, identificar semelhanças e diferenças na vida de alguns animais

A atividade consistiu na leitura (com sinais) de legendas com informações a respeito de característi- cas e hábitos de animais e observação de gravuras coloridas suas. A proposta era de que Janete estabelecesse relações de semelhanças e diferenças entre os animais, apresentados na seguinte ordem: mico-leãodourado, lobo-guará, arara azul, onça-pintada e jacaré-de-papo-amarelo. O tema era "animais em extinção"; as legendas foram lidas pela educadora; Janete demonstrou grande interesse em saber as características de cada um, olhando as figuras bem de perto e pedindo que a educadora lesse.

Destacou-se a situação em que Janete estabeleceu semelhanças entre o lobo-guará e a onça-pintada.

Janete - Antes da leitura da legenda, olha a gravura da onça-pintada, faz sinal de pintas, dizendo que era uma onça pintada; lê o nome do animal e comenta que pensou que suas manchas eram pintura.

Educadora - Explica para Janete que a onça não é uma pintura, ela tem este nome porque seu corpo apresenta manchas, que parecem ser pintadas.

Janete - faz comentários pertinentes sobre as manchas, dizendo sua cor e qualificando o animal de bonito.

Educadora - Lê a legenda da gravura da onçapintada.

Janete - comenta, dizendo que os dois animais, a onça-pintada e o lobo-guará são iguais, pelo fato de terem hábitos noturnos.

Educadora - confirma a informação, falando que os animais gostam de caçar à noite.

A partir da observação de gravuras dos animais, Janete demonstra interesse em ter informações sobre hábitos e características dos mesmos. Olha as figuras de perto, inicia diálogos, pede para a educadora ler as legendas, passa o dedo em cima das gravuras, comenta sobre os animais; durante a leitura das legendas, faz perguntas para esclarecimento do vocabulário desconhecido e estabelece semelhanças entre os animais que possuem os mesmos hábitos. Mantém a atenção durante toda a atividade, pergunta e comenta a respeito dos animais observados.

Nesta atividade, pode-se verificar que com apoio das imagens e mediações (leitura, explicação, 
esclarecimento de vocabulário, observação da gravura) o interesse de Janete cresce e faz com que seu conhecimento sobre o mundo se amplie.

SITUAÇÃO 6 - Sessão 3. Atividade 2: Pintar, relacionando animais, coisas ou pessoas com situações de vida diária

A proposta desta atividade era que Janete utilizasse a pintura para representar o significado real das frases metafóricas, lidas com a educadora, conforme descritas no Quadro I. Foram apresentadas quatro frases; no primeiro momento, a educadora pediu-lhe que escolhesse uma frase. Janete pediu para a educadora pintar junto com ela, então ela escolheu duas frases e a educadora duas, para serem representadas através da pintura.

Enquanto pintava, representando o significado da frase "Tem dias que estamos acabados", Janete fez algo fora da proposta inicial, transferindo da pintura para uma situação que havia vivenciado, a ida, num final de semana, com sua mãe, a um ateliê de pintura onde são oferecidas oportunidades de expressão artística, numa proposta aberta.

Janete pega a folha e começa a desenhar. Chama a atenção com a mão, batendo no braço da educadora para que olhe o desenho. Desenha uma pessoa pintando, sentada em uma mesa e faz o sinal de casa. A educadora pergunta quem é a pessoa que está pintando, ela responde que é ela, depois desenha uma outra pessoa que diz ser o Rafael, escreve o nome: Rafael. A educadora pergunta se ele está pintando, ela ri e diz que não, que ele tinha pintado no dia anterior; faz sinal de "depois", explicando que outra pessoa pintou depois. Escreve o nome de várias pessoas que pintaram, olha a folha em que estão escritos os nomes, para e olha para a educadora; escreve "Rafael" três vezes; a educadora pergunta se eram três pessoas com nome de Rafael e se ela estava junto pintando. Janete responde que sim e que cada um foi pintando, um após o outro.

A educadora olha o desenho, em que Janete está representando o ateliê, e pergunta quem estava sentado na mesa, pintando; responde que era ela e que tinha muitas pessoas pintando; olha para a folha dos nomes, ri e desenha na outra folha a pessoa da qual acaba de ler o nome.

Desenha as pessoas numa ordem, do maior (mais perto) ao menor (mais longe). Janete continua olhando e desenhando as pessoas. Desenha a si mesma pintando e os amigos esperando. Janete escreve o nome de cada amigo embaixo do desenho feito. A educadora ajuda a associar o nome ao desenho..

A partir da atividade proposta (pintura), Janete representa, por meio do desenho, uma situação vivenciada no seu dia-a-dia. Partindo de uma atividade de pintura direcionada, faz relação com uma experiência de pintura em outra situação, com outras pessoas. Desenha e escreve o nome das pessoas que pintaram, organiza o relato de fatos ocorridos com

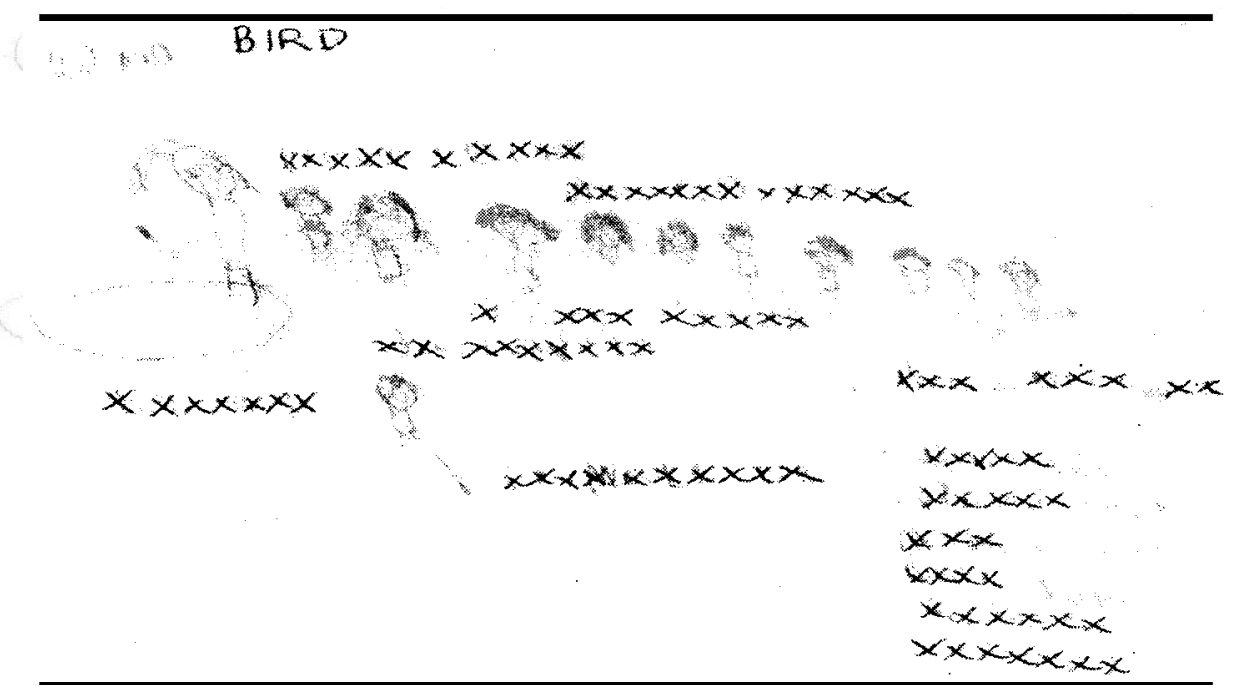

Figura 3: Desenho do Ateliê 


\section{Clarisse Alabarce Nery}

ela, de forma a deixar claro que era um lugar diferente e que tinha muitas pessoas. Faz o desenho das figuras humanas em diferentes tamanhos, parecendo tentar uma representação em perspectiva. Traz elementos novos para a atividade proposta e para um diálogo com a educadora. Nesta atividade, pode-se verificar como Janete transpõe seu conhecimento, do que lhe é proposto para fazer uma vinculação com a realidade. Interagindo com a educadora, realiza conversas que possibilitam a compreensão de significados diferentes, e percepção de atributos que as imagens oferecem. Percebe-se que representa conceitos de forma mais generalizada e dinâmica.

Conforme destacado, os exemplos apresentados foram selecionados dentre os melhores desempenhos de Janete. Em relação às fotos do livro "Um dia daqueles”, sua participação centrou-se na descrição dos atributos dos animais fotografados, sem fazer relações metafóricas, que foram apresentadas pela educadora, em diálogos que contaram com o interesse de Janete. Entretanto, não ficou explícita a compreensão das referidas metáforas, o que pode ter ocorrido, em alguns casos, na reapresentação das atividades. De modo geral, considera-se que Janete manteve diálogos mais extensos que usualmente, abordando elementos descritivos e estabelecendo mais relações e inferências do que habitualmente.

\section{Discussão e Conclusão}

Com base nos registros feitos pela educadora, após cada encontro com Janete, alguns aspectos foram percebidos e desenvolvidos, no decorrer das atividades. Observou-se o desenvolvimento de uma prática discursiva com diálogos extensos, abordando elementos descritivos e estabelecendo relações e inferências entre os assuntos propostos. Janete apresentou um nível de atenção e de participação maior que a habitual, com elaboração dos temas propostos e capacidade de compreensão em níveis diferentes de complexidade, o que esteve associado às atividades com uso intensivo de imagens visuais. Para uma jovem que tinha dificuldade em manter um diálogo, uma experiência discursiva, ela mostrou mudanças significativas. Com o uso das representações visuais, suas interações com a educadora foram se tornando cada vez maiores e mais ricas. Utilizando as gravu- ras de objetos de arte (de natureza polissêmica, com mais de um atributo, função e sentido) e seus desenhos, Janete estabeleceu relações de seus conhecimentos com a vida cotidiana (pensamento relacional), e seus diálogos se tornaram mais elaborados. As representações visuais favoreceram uma conversação, maior concentração e manutenção do diálogo.

As observações das fotos do livro e leitura das frases metafóricas possibilitaram o início da compreensão de conceitos diferentes e mais complexos para Janete, a partir dos comentários sobre atributos diretos das imagens visuais, pôde extrapolar sobre o significado das mesmas. As próprias pinturas realizadas por Janete demonstraram uma compreensão de significados e relações com fatos que ocorrem no dia-a-dia, possibilitando a transferência destes conceitos para outras situações vivenciadas por ela, exemplificado no caso da visita ao ateliê de pintura.

O trabalho de Reily (2003), utilizando a imagem visual como recurso pedagógico, constituiu-se em ponto de partida para o presente trabalho, na medida em que despertou o desafio de realizá-lo com pessoas surdas com mais idade, diferentes das que participaram da proposta inicial. A idéia se mostrou fecunda. Selecionando-se imagens e atividades apropriadas à idade e nível de conhecimento de Janete, foi possível estabelecer interações mais ricas que as habitualmente desenvolvidas sem o uso intensivo desse recurso.

A resposta de Janete a propostas educacionais alternativas traz uma reflexão sobre a questão da metodologia utilizada nas escolas, tendo em vista a inclusão. O uso de imagens visuais parece representar um recurso bastante significativo para o aluno surdo, além de pedagógico, possibilitando um desenvolvimento cognitivo mais significativo, viabiliza a criação de um contexto inclusivo mais adequado às suas necessidades, oferecendo uma forma visual de acesso ao conhecimento e uma alternativa para que a comunicação do surdo, de fato, aconteça na escola.

Pensando na população dos jovens surdos, verifica-se que, na nossa sociedade, existem poucos recursos e espaços culturais onde possam dar continuidade ao seu desenvolvimento cognitivo, iniciado, seja nas escolas especiais, seja nas inclusivas com o intérprete de sinais.

A questão é saber por que existem poucas es- 
colas e centros de convivência em que esteja disponível a Língua de Sinais e outros recursos para atender a pessoas surdas, especialmente as que apresentem algumas dificuldades e especificidades, como no caso de Janete. Discute-se por que não foi possível a participação e a aprendizagem de Janete no sistema formal de ensino. Por que ela, que demonstra competências em uma situação planejada e adequada a suas capacidades, ficou fora da escola na adolescência?

Considera-se que o presente estudo indica a possibilidade de se pensar em recursos facilitadores da aprendizagem do surdo. A adoção de imagens visuais pode ser um deles, assim como outros recursos devem ser explorados, descobertos e até mesmo criados com o objetivo de possibilitar uma metodologia e um currículo escolar que seja adequado às diferenças do aluno surdo, possibilitando sua real inclusão na escola.

\section{Referências Bibliográficas}

Andretta, S. (1999). Atelier de Criatividade em gravura como fonte mediadora nos processos de interação educativa. [Resumo] Em: Encontro Anual de Iniciação Científica. São José dos Campos. SP. UNIVAP. Anais.../ Universidade do Vale do Paraíba.

Boneti, R. V. F. (2000). A organização escolar e a inclusão das diferenças na sala de aula: só as adaptações curriculares resolvem? [Resumo] Cap. IX (pp. 85-91). Trabalho apresentado no III Congresso Brasileiro sobre Síndrome de Down. Anais. Curitiba. Brasil.

Góes, M. C. R. (2000). Com quem as crianças surdas dialogam em sinais? Em C. B. F. Surdez: Processos Educativos e Subjetividade. Cap. III. (pp. 29-49) SP: Editora Lovise.

Kassar, M. C. M. (1999). Deficiência múltipla e educação no Brasil: discurso e silêncio na história de sujeitos. Campinas. SP, Autores Associados.

Lacerda, C. B. F. (2000). O intérprete de Língua de Sinais no contexto de uma sala de aula de alunos ouvintes: problematizando a questão. Em Sur- dez: Processos Educativos e Subjetividade Cap. IV. (pp.51-84). SP: Editora Lovise.

Padilha, A. M. L. (2001). Práticas pedagógicas na educação especial: a capacidade de significar o mundo e a inserção cultural do deficiente mental. Campinas. SP, Autores Associados.

Reily, L. H. (2003). As imagens: o lúdico e o absurdo no ensino de arte para Pré- escolares surdos. Em I. R.Silva; S. Kauchakje \& Z. M.Gesueli (Orgs.), Cidadania, Surdez e Linguagem: desafios e realidades. Cap. IX (pp.161-192).SP: Plexus Editora.

Sacks, O. (1998). Vendo Vozes: uma viagem ao mundo dos surdos. SP: Companhia das Letras.

Vygotsky, L. S. (1989). Pensamento e linguagem. (Tradução Brasileira da tradução Inglês do original Russo de 1934). SP: Martins Fontes, $2^{\mathrm{a}}$ edição. 